\title{
A Forgotten Disease in the Land of Citrus Fruit
}

\section{Neri $S^{1}$, Pollicino $C^{2}$, Rizzotto $A^{3}$ and Arcidiacono $E^{2 *}$}

${ }^{1}$ Department of Internal Medicine, University of Catania- A.O.U. Policlinico G. Rodolico, Italy

${ }^{2}$ Department of Psychiatry, University of Catania- A.O.U. Policlinico G. Rodolico, Italy

${ }^{3}$ School of Psychology, University KORE Enna, Italy

\begin{abstract}
Scurvy is a nearly-forgotten disease in developed countries where adequate nutrition is easily available, the few cases of scurvy reported in the 21 st century have mainly occurred in the neglected elderly, alcoholics and food faddist. Nutritional deficiency, however, may be a presenting sign of undiagnosed psychiatric illness (eating disorders, psychotic depression and Obsessive Compulsive Disorder-OCD). We report the case of a 15-year-old patient with depression who developed scurvy as a secondary complication to a primary psychiatric pathology regarding depression. With vitamin C replacement, psychiatric medication and behavioural therapy there was an improvement in his condition. We strongly recommend a high index of suspicion for this disease in the specific populations at risk, described as the socially isolated adult or elderly patient with a history of destructive behavior, who lives alone, and is mentally or chronically ill. The early identification of a psychiatric pathology and a good and prompt treatment can, in fact, improve the course of the illness and its prognosis.
\end{abstract}

Keywords: Scurvy; Vitamin C deficiency; Psychiatric Disorders; Depression

\section{Introduction}

Nutritional deficiency may be a presenting sign of undiagnosed psychiatric illness. It is important to remember that nutritional deficiency is not always the final diagnosis, but may be a sign of an underlying, unrecognized psychiatric disorder [1]. Some patients, particularly those with eating disorders, psychotic depression and OCD may try to hide or deny their underlying psychopathology. In this case report, we describe scurvy as a secondary complication of the primary psychiatric pathology regarding depression. Scurvy has been known to exist for more than 2 millennia [2]. Historically, scurvy was associated with sailors during periods of lengthy navigation. This disease has been known since ancient Egypt, but nowadays it has almost been forgotten [3]. It is still occasionally encountered in adults with poor and or unbalanced diets, i.e. alcoholics, elderly patients, the homeless, and food faddists [2]. Recognizing the disease requires heightened vigilance, patients may require a referral for psychiatric evaluation [1], so is very important to highlight that, in a subject with psychiatric disorders and co-morbidity, only a multidisciplinary approach permits a correct diagnosis and optimum patient care. The early identification of psychiatric pathology, and good and prompt treatment improve the course of the illness and the prognosis. To maximize results, treatment should include pharmacological therapy in addition to behaviour therapy.

\section{Case Report}

$$
\text { A.P. } 15 \text { year-old boy living in Sicily. }
$$

\section{Family history}

There was no family history of mental illness or eating disorders the patient's parents divorced when he was 9 years old and he lived with his grandmother. His father had remarried and lived in an other country; his mother lived with another man two hundred miles away.

\section{Physiological history}

Full term delivery. Normal somatic and psychic development. Attend primary school. No drinking, no smoking. Denies the presence of allergies. He was not taking any drugs that are known to cause gingival enlargement, such as phenytoin, nifedipine, or lithium.

\section{Medical history}

He refers common childhood exanthematous diseases. He does not recall other relevant diseases.

\section{Premorbid personality}

The analysis of the premorbid period reveals the presence of a depressive temperament characterized by scepticism, feelings of inadequacy, rumination. He feels neglected and not sufficiently valued by his parents. He describes himself as an introverted child with few interpersonal relationships. The patient was overweight and he had the perception of being ignored.

\section{Recent pathological history}

He was admitted to our hospital with a presumptive diagnosis of vasculitis because of a recent onset of a rash resembling palpable purpura (see Figure 1: A). On admission he presented a wide-based gait, walked slowly and reached out for support. There was gingival swelling with bleeding (see Figure 1: B) and malposition of teeth. Petechiae were present on both legs up to the thigh, localized around hair follicles; coiled hairs and hyperkeratosis were also noted. There was a full range of passive motion of all joints except for the knees which could not be flexed without causing pain. The lungs and the heart were normal. The abdomen appeared slightly expanded with striae (stretch marks) (see Figure 1: C). The abdominal findings, suggesting a significant loss of weight, and the development of skin lesions and gingival bleeding, raising the suspicion of vitamin $\mathrm{C}$ deficiency. The diagnosis of scurvy was confirmed by the serum vitamin $\mathrm{C}$ level which was less than $0.10 \mathrm{mg} / \mathrm{dl}$ (normal range 0.20-2.00). The disease seemed to be absent in Sicily (only one case referred in literature) due to the

*Corresponding author: Eleonora Arcidiacono, University of Catania- Department of Psychiatry- A.O.U. Policlinico G. Rodolico, via S. Sofia, 78 Catania, Italy, Tel: +390953782470; Fax: +390953782470; E-mail: eleonoraarcidiacono@hotmail.com

Received November 03, 2011; Accepted February 11, 2012; Published February 13,2012

Citation: Neri S, Pollicino C, Rizzotto A, Arcidiacono E (2012) A Forgotten Disease in the Land of Citrus Fruit. J Nutr Disorders Ther 2:106. doi:10.4172/21610509.1000106

Copyright: (c) 2012 Neri S, et al. This is an open-access article distributed under the terms of the Creative Commons Attribution License, which permits unrestricted use, distribution, and reproduction in any medium, provided the original author and source are credited. 


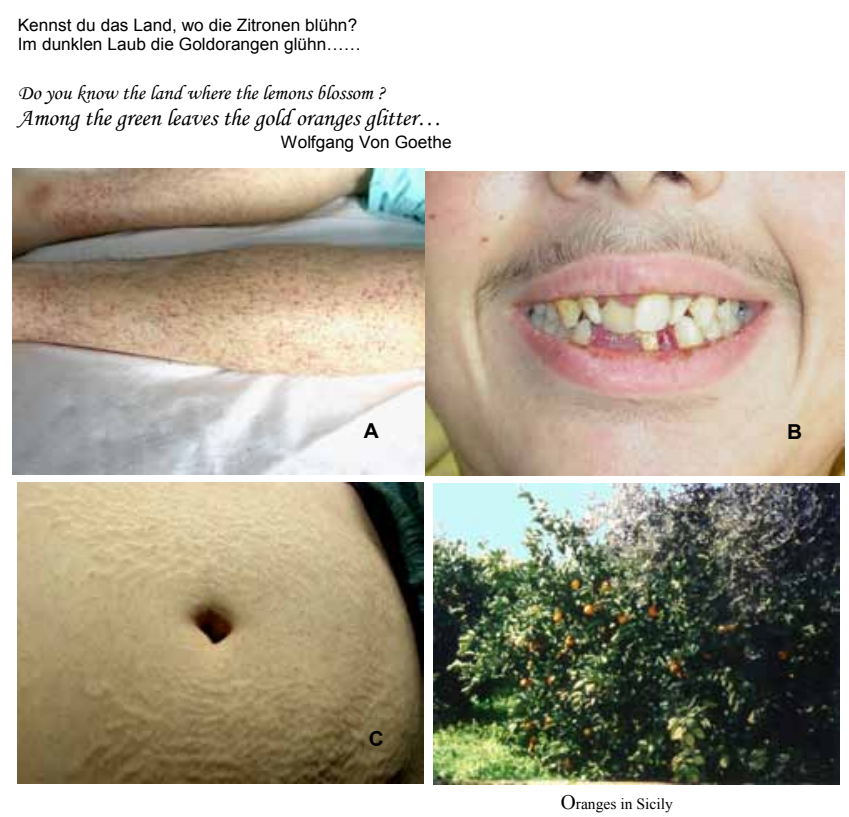

Figure 1: A) purpura B) gingival swelling with bleeding C) slightly expanded abdomen with striae.

wide local availability of fruit with high ascorbic acid level that can protect against scurvy. This observation may explain the absence or paucity of this disease throughout Sicily, whatever the standards of living. In addition, the patient presented sleep disturbance, change in school performance, diminished socialization, anhedonia and a significant loss of weight. He also presented obsessive and distorted thoughts about his weight. Gives his history we know that he gradually restricted his diet; he had decided to follow a self-made diet: for three months he had consumed only one or two slices of bread a day, he walked every day (for seven-ten kilometres). He had lost $14 \mathrm{Kg}$. After the third month of this diet, he began to present knee pain followed by cutaneous hemorrhagic symptoms. The psychiatric examination revealed a fully oriented, anxious, depressed boy. The facial expression expressed feelings of sadness. The attitude was cooperative and he was willing to talk with the health personnel. His speech was spontaneous and expressed with a low voice. He appeared not to be actively hallucinating and had no neurological complaints. His memory was preserved. His mood was depressed with loss of interest in his usual activities, loss of appetite and weight loss, difficulties with falling asleep and with concentrating and fatigue. At the interview low self-esteem emerged with feelings of inadequacy, and intrusive thoughts of being fat. The situation was complicated by his habits and the aversion to going out and socializing. In this case the compulsory admission for treatment wasn't necessary. After diagnosis of scurvy, Vitamin C $(1000 \mathrm{mg} /$ day i.v.) a multivitamin therapy was immediately begun, and by the fourth day the patient began to walk. Petechiae disappeared completely within ten days. Olanzapine, $5 \mathrm{mg} /$ day and Sertraline, $150 \mathrm{mg} /$ day were given to minimize obsessive and distorted thoughts and depressive symptoms respectively. The treatment with drugs and vitamin $\mathrm{C}$ rapidly replace produced remission of mental and physical symptoms; improvement was maintained by continuing antipsychotic medication, psychological counselling, comprehensive follow up, and collaboration with the general practitioners. As his medical condition improved during hospitalization, a multidisciplinary therapy program was initiated including cognitive behaviour therapy with a psychiatrist, counselling with a nutritionist, psychological counselling.

\section{Discussion}

Scurvy is a disease resulting from vitamin $\mathrm{C}$ deficiency that occurs because of a reduced intake or absorption of vitamin C. At-risk groups includes the poor (because of reduced access to groceries), food faddists, widowers, alcoholics, individuals with psychiatric disorders and purported allergies to multiple fruit and vegetable products. The diagnosis of scurvy is generally based on clinical features, dietary history and the rapid lack of symptoms after vitamin C supplementation [4-5]. The laboratory can confirm less typical cases [4-5]. Fresh fruit, vegetables and also synthetic tablets supplement the ascorbic acid requirement of the body. All physicians should be aware of the clinical presentations of vitamin $\mathrm{C}$ deficiency, especially in young adolescents, but in subjects treated by parenteral nutrition also, because its presentation may be subtle [5-6]. Scurvy usually occurs in patients with poor nutrition; our opinion is that the most likely cause of our patient's poor nutrition was depression linked with the psychosocial context. In this case report the patient, in relation with an emotional distress, developed a depressive episode in which intrusive thoughts about food were present, which led to a drastic reduction of it. Studies suggest that depression often occurs in adolescents who have problems in areas of psychosocial functioning [7]. For example, negative relationship characteristics including relationship break-up, bullying, lower parental trust, higher levels of family conflict and greater levels of familial alienation [8-10]. It has been suggested that high levels of interparental conflict might lead to changes in parenting style that would in turn negatively affect children. The emotional distress and distractions of interparental conflict drain parental resources and make it less likely that parents will provide children with warmth, support, and structure, which in turn negatively impact children's emotional well-being [11]. The mechanisms by which conflict affects children's well-being has tended to focus on two possibilities: the first suggests that interparental conflict leads to maladaptive parenting, which in turn leads to child maladjustment [12], the second proposes that the impact of conflict is mediated in part by children's cognitions, specifically, their attributions regarding the cause of conflict and their perceptions of their own ability to affect the conflict [13]. In this case report, we describe scurvy as a complication of a depression episode with obsessive thoughts regarding diet. Nutritional deficiencies in the context of psychiatric disorders are in fact quite frequent and they may depend on different factors. Psychotic patients exhibiting negative symptoms such as anhedonia or loss of function may have decreased intake, and those with positive symptoms like paranoia or delusions regarding food may restrict their diets [14]. Scurvy has also been reported as a consequence of suicide attempt by self-starvation [15] and in the setting of other psychiatric illnesses, such as eating disorders, alcoholism [1] and OCD [16]. General practitioners and psychiatrists should work together to ensure early diagnosis and comprehensive treatment of cases such as this one. This shows the importance of consultation-liaison psychiatry, which helps to determine professional relationships, seeing patients in collaboration with practitioners, holding regular face-to-face contacts and meetings with staff in primary care. As noted physicians should pay attention to physical as well as emotional manifestations of serious disease. In fact although the medical diagnosis in this case was not difficult, the treatment of underlying psychopathology is crucial to preventing further episodes of malnutrition. This case serves as a reminder to the clinician that, even though rare in today's practice, ascorbic acid deficiency can still be encountered, and when recognized is an easily treatable disease.

\section{References}

1. Arron ST, Liao W, Maurer T (2007) Scurvy: a presenting sign of psychosis. $J$ Am Acad Dermatol 57: S8-10. 
2. Estienne M, Bugiani M, Bizzi A, Granata T (2011) Scurvy hidden behind neuropsychiatric symptoms. Neurol Sci 32: 1091-1093.

3. Vieira AA, Minicucci MF, Gaiolla RD, Okoshi MP, Duarte DR, et al. (2009) Scurvy induced by obsessive-compulsive disorder. BMJ Case Rep.

4. Olmedo M, Yiannias JA, Windgassen AB, Gornet MK (2006) Scurvy: A disease almost forgotten. Int J Dermatology 45: 909-913.

5. Weinstein M, Babyn P, Zlotkin S (2001) An orange a day keeps the doctor away: Scurvy in the year. Pediatrics; 108: E55.

6. Gidding SS, Dennison BA, Birch LL, Daniels SR, Gillman MW, et al. (2006) Dietary recommendations for children and adolescents: A guide for practitioners. Pediatrics 117: 544-559.

7. Steele RG, Armistead L, Forehand R (2000) Concurrent and longitudinal correlates of depressive symptoms among low-income, urban, African American children. Family Healt Projet Research Group. J Clin Child Psychology 29: 7685.

8. Klomeck AB, Marrocco F, Kleinman M, Schoenfeld IS, Gould MS (2007) Bullying, depression and suicidality in adolescents. J Am Acad Child Adolesc Psychiatry 46: 40-49.

9. Connell AM, Goodman SH (2002) The association between psychopathology in fathers versus mothers and children's internalizing and externalizing behavior problems. Psychol Bull 128: 746-773.
10. Starr LR, Davila J (2008) Differentiating interpersonal correlates of depressive symptoms and social anxiety in adolescence: Implications for models of comorbidity. J Clin Child Adolesc Psychol 37: 337-349.

11. McLeod B, Weisz J, Wood J (2007) Examining the association between parenting and childhood depression: A meta-analysis. Clin Psychol Rev 27 986-1003.

12. Cox MJ, Paley B, Harter K (2001) Interparental conflict andparent-child relationships. Interparental conflict and child development. NY: Cambridge University Press.

13. Grych JH, Cardoza-Fernandez S (2001) Understanding the impact of interparental conflict on children: The role of socialcognitive processes. Interparental conflict and child development. NY: Cambridge University Press.

14. Schulze F, Banzhaf M (1981) Vitamin B12 deficiency syndrome and vitamin C avitaminosis in psychotic malnutrition. Psychiatr Neurol Med Psychol (Leipz) 33: 500-5033.

15. Stoger H, Wilders-Truschnig M, Schmid M, Petek W, Samonigg H. (1994) [Scurvy after a suicide attempt by starvation.] Dtsch Med Wochenschr 119 589-92.

16. Yaegaschi MY, Torres AR (2010) Scurvy, anemia and malnutrition secondary to obsessive compulsive disorder. Rev Bras Psiquiatr 32: 198-199. 